\title{
Dynamic Deformation Behaviour and Dislocation Substructure of AZ80 Magnesium Alloy over a Wide Range of Temperatures
}

\author{
Woei-Shyan Lee*, and Cheng-Wen Chou \\ Department of Mechanical Engineering, National Cheng Kung University, Tainan 701, Taiwan
}

\begin{abstract}
The high strain rate deformation behaviour and dislocation substructure of AZ80 magnesium alloy are investigated at strain rates of $8 \times 102 \mathrm{~s}-1,1.5 \times 103 \mathrm{~s}-1$ and $2.2 \times 103 \mathrm{~s}-1$ and temperatures of $-100{ }^{\circ} \mathrm{C}$, $25{ }^{\circ} \mathrm{C}$ and $300{ }^{\circ} \mathrm{C}$ using a compressive split-Hopkinson pressure bar system. The flow stress, work hardening coefficient, strain rate sensitivity and temperature sensitivity all increase with increasing strain rate or decreasing temperature. Moreover, the dynamic deformation behaviour is well described by the Zerilli-Armstrong hep constitutive equation. Transmission electron microscopy observations show that the dislocation density increases with a higher strain rate or a lower temperature. Finally, the flow stress varies linearly with the square root of the dislocation density in accordance with the Bailey-Hirsch model.
\end{abstract}

\section{Introduction}

Magnesium alloys have many favourable properties, including a low density, a high strength-to-weight ratio, excellent machinability, and good recyclability. As a result, they have received extensive attention in recent years as structural components for transportation and aerospace applications, and lightweight enclosures for 3C (computer, communication and consumer electronic) products [1-2]. With a high strength and a low price, AZ80 magnesium alloy is one of the most widely-used commercial magnesium alloys [3-4]. The mechanical properties and microstructure [5], or creep behaviour [6], or extrusion deformation [7] and weldability [8] of AZ80 are all well-understood. AZ80 magnesium alloy components often experience high strain rate loads during fabrication or in their subsequent service lives.

However, the literature contains only limited information regarding the high strain rate forging behaviour of AZ80. Thus, to ensure the physical integrity of AZ80 structural components, a more rigorous evaluation of the effects of strain rate and temperature on the flow behaviour and dislocation substructure of AZ80 magnesium alloy is required.

The present study investigates the high strain rate deformation behaviour of AZ80 magnesium alloy at strain rates of $8 \times 10^{2} \mathrm{~s}^{-1}, 1.5 \times 10^{3} \mathrm{~s}^{-1}$ and $2.2 \times 10^{3} \mathrm{~s}^{-1}$ and temperatures of $-100{ }^{\circ} \mathrm{C}, 25{ }^{\circ} \mathrm{C}$ and $300{ }^{\circ} \mathrm{C}$ using a compressive split-Hopkinson pressure bar (SHPB) system. The correlation between the flow stress and the dislocation density is then investigated as a function of the strain rate and temperature.

\section{Experimental procedure}

The starting material for the impact tests was an extruded rod of AZ80 (Al 8, Zn 0.5 and a balance of Mg (wt. \%) alloy with a $12 \mathrm{~mm}$ diameter. The rod was solution treated at $410{ }^{\circ} \mathrm{C}$ for $12 \mathrm{~h}$ followed by water quenching, and then aged at $230{ }^{\circ} \mathrm{C}$ for $8 \mathrm{~h}$. Cylindrical specimens with a length of $8 \pm 0.1 \mathrm{~mm}$ and a diameter of $7.2 \mathrm{~mm}$ were machined from the heat-treated AZ80 alloy with the impact axis parallel to the extruded direction and finished to a final diameter of $7 \pm 0.1 \mathrm{~mm}$ via a centre-grinding process. To approximate a uniaxial deformation state during deformation (i.e., low friction conditions), the end faces of the specimens were lubricated with a glass paste consisting of $80 \% \mathrm{PbO}$ and $20 \% \mathrm{~B} 2 \mathrm{O} 3$ mixed with alcohol.

High strain rate forging tests were performed at strain rates of $8 \times 10^{2} \mathrm{~s}^{-1}, 1.5 \times 10^{3} \mathrm{~s}^{-1}$ and $2.2 \times 10^{3} \mathrm{~s}^{-1}$ and temperatures of $-100{ }^{\circ} \mathrm{C}, 25^{\circ} \mathrm{C}$ and $300{ }^{\circ} \mathrm{C}$ using the compressive SHPB system. The low testing temperature of $-100{ }^{\circ} \mathrm{C}$ was obtained by immersing the specimen in a refrigeration system filled with liquid nitrogen and alcohol. Meanwhile, the elevated deformation temperature of $300{ }^{\circ} \mathrm{C}$ was achieved by enclosing the specimen in a clamshell radiant-heating furnace.

The microstructures and morphologies of the various specimens were observed by transmission electron microscopy (TEM). TEM foils were prepared using an FEI Nova 200 focused ion beam (FIB) milling system with a $\mathrm{Ga}$ ion beam and an operating voltage of $30 \mathrm{keV}$. The cross-sectional microstructures of the various specimens were observed using a Philips Tecnai F30 field emission gun transmission microscope with an operating voltage of $300 \mathrm{keV}$. The dislocation density $\rho$ of each sample was calculated using Ham's interception method [9]. 


\section{Results and discussion}

\subsection{Flow stress-strain behaviour}

Figures 1(a) 1(c) show the true stress-strain curves of the AZ80 specimens forged at strain rates of $8 \times 10^{2} \mathrm{~s}^{-1}$, $1.5 \times 10^{3} \mathrm{~s}^{-1}$ and $2.2 \times 10^{3} \mathrm{~s}^{-1}$ and temperatures of $-100{ }^{\circ} \mathrm{C}$, $25^{\circ} \mathrm{C}$ and $300{ }^{\circ} \mathrm{C}$, respectively. It is seen that the flow stress curves have a parabolic shape under all of the considered loading conditions. However, the flow stress is sensitive to both the temperature and the strain rate.

For a given temperature, the flow stress increases with increasing strain rate. However, for a given strain rate, the flow stress decreases as the temperature increases. In other words, even though the flow curves have a similar shape, the specimens exhibit different degrees of work hardening and thermal softening under different strain rates and temperatures. This finding suggests that the dislocation density and multiplication rate both vary widely with the strain rate and temperature, and prompt a corresponding change in the plastic deformation resistance of the AZ80 specimens.

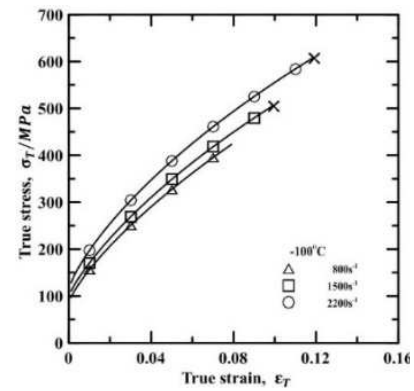

(a)

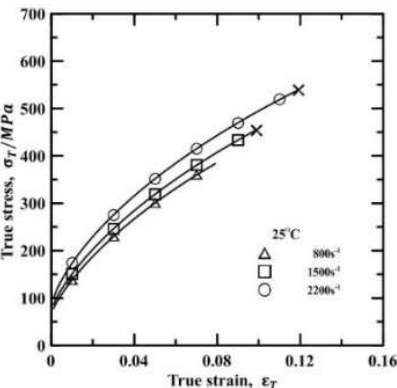

(b)

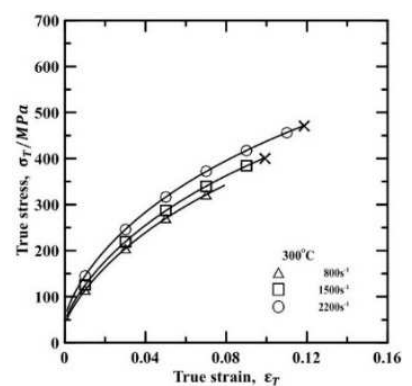

(c)

Fig. 1. Stress-strain curves of AZ80 specimens forged at temperatures of: (a) $-100{ }^{\circ} \mathrm{C}$, (b) $25^{\circ} \mathrm{C}$, and (c) $300{ }^{\circ} \mathrm{C}$ under strain rates of $8 \times 10^{2} \mathrm{~s}^{-1}, 1.5 \times 10^{3} \mathrm{~s}^{-1}$ and $2.2 \times 10^{3} \mathrm{~s}^{-1}$.

\subsection{Effects of strain rate and temperature}

Figure 2(a) shows the variation of the true stress with the strain rate as a function of the temperature and true strain $\left(\varepsilon_{\mathrm{t}}=0.015\right.$ and 0.07$)$. For both values of the true strain, the true stress increases linearly as the strain rate is increased from $8 \times 10^{2} \mathrm{~s}^{-1}$ to $1.5 \times 10^{3} \mathrm{~s}^{-1}$ and $1.5 \times 10^{3} \mathrm{~s}^{-1}$ to $2.2 \times 10^{3} \mathrm{~s}^{-1}$. However, the increase in the flow stress is more rapid in the higher strain rate range of $1.5 \times 10^{3} \mathrm{~s}^{-1}$ to $2.2 \times 10^{3} \mathrm{~s}^{-1}$. Overall, the results presented in Fig. 2(a) suggest that the rate of dislocation multiplication and work hardening increases under an increasing strain rate or a decreasing temperature.

Figure 2(b) shows the variation of the strain rate sensitivity with the strain as a function of the strain rate and temperature. It is seen that for a given strain and deformation temperature, the strain rate sensitivity increases rapidly with increasing strain rate; particularly in the higher strain rate range of $1.5 \times 10^{3}$ to $2.2 \times 10^{3} \mathrm{~s}^{-1}$. Moreover, for a given strain rate range, the strain rate sensitivity increases with increasing strain, but decreases with increasing temperature. The higher strain rate sensitivity under higher strain rates and lower temperatures can be attributed to a more rapid multiplication of the dislocations during deformation.

The dislocations serve as effective obstacles in suppressing further dislocation motion, and therefore increase the flow resistance.

Figure 3(a) shows the variation of the flow stress with the deformation temperature as a function of the strain rate for true strains of 0.15 and 0.45 , respectively.

An obvious thermal softening effect is observed under higher temperatures for all values of the strain and strain rate. Figure $3(\mathrm{~b})$ shows the variation of the temperature sensitivity with the true strain as a function of the strain rate over the temperature ranges of $-100{ }^{\circ} \mathrm{C}$ to $25^{\circ} \mathrm{C}$ and $25^{\circ} \mathrm{C}$ to $300{ }^{\circ} \mathrm{C}$, respectively. It is observed that for a constant strain and strain rate, the temperature sensitivity decreases with increasing temperature. However, for both temperature ranges, the temperature sensitivity increases as the strain and strain rate increase.

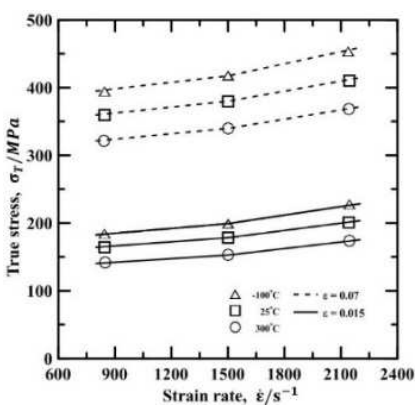

(a)

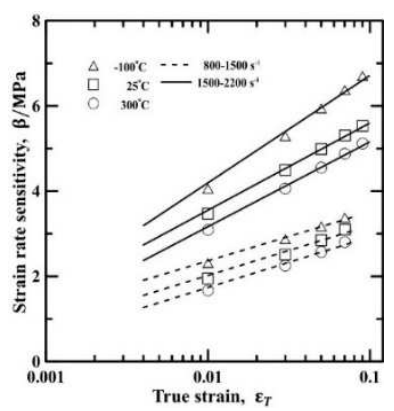

(b)
Fig. 2. (a) Variation of true stress with strain rate as function of temperature given true strains of 0.015 and 0.07. (b) Variation of strain rate sensitivity with true strain as function of temperature and strain rate.

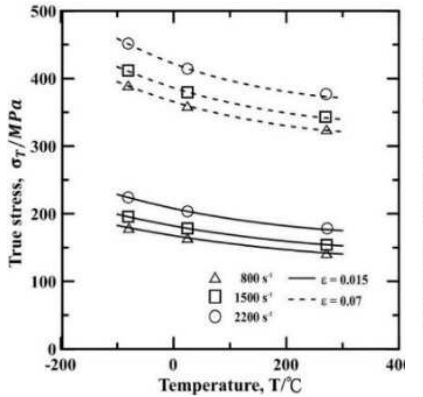

(a)

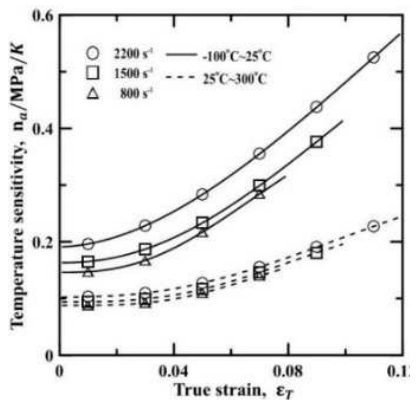

(b)
Fig. 3. (a) Variation of true stress with temperature as function of strain rate given true strains of 0.015 and 0.07. (b) Variation of temperature sensitivity with true strain as function of temperature and strain rate. 


\subsection{Deformation constitutive equation}

Zerilli and Armstrong [10] proposed a constitutive equation for describing the intermediate behaviour of hcp materials in terms of Peierls stress interactions (predominant in bcc structures) and intersection-of-forest dislocation type interactions (predominant in fcc structures). The ZA model has the form

$$
\begin{gathered}
\sigma=\sigma_{\mathrm{a}}+\mathrm{B} \exp (-\beta \mathrm{T})+\mathrm{B}_{0} \varepsilon^{1 / 2} \exp (-\alpha \mathrm{T}) \\
\beta=\beta_{0}-\beta_{1} \ln (\dot{\varepsilon}) \\
\alpha=\alpha_{0}-\alpha_{1} \ln (\dot{\varepsilon})
\end{gathered}
$$

where $\sigma_{\mathrm{a}}, \mathrm{B}, \beta_{0}, \beta_{1}, \mathrm{~B}_{0}, \alpha_{0}$ and $\alpha_{1}$ are constants; $\sigma$ is the stress; $\varepsilon$ is the equivalent plastic strain; $\dot{\varepsilon}$ is the strain rate; and $\mathrm{T}$ is the deformation temperature.

Employing the parameter evaluation method described in [10], and using the stress-strain values given in Fig. 1, the corresponding parameter values for the ZA model are found to be $\mathrm{C}_{0}=413.52 \mathrm{MPa} ; \mathrm{C}_{2}=1605.42$ MPa; $\mathrm{C}_{3}=1.84 \times 10^{-2} \mathrm{~K}^{-1} ; \mathrm{C}_{4}=1.86 \times 10^{-3} \mathrm{~K}^{-1}$; and $\mathrm{n}=$ 0.756. Figures 4(a) and 4(b) compare the flow curves obtained by Eq. (1) for the present AZ80 specimens with the experimental curves shown in Fig. 4. It is seen that a good qualitative agreement exists between the two sets of results for all values of the strain rate and temperature.

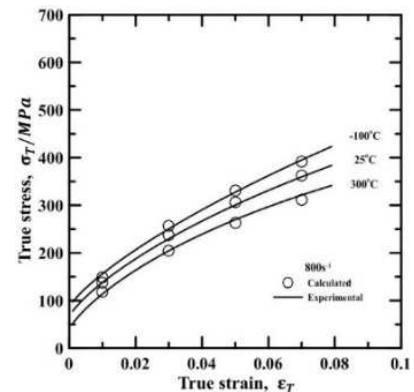

(a)

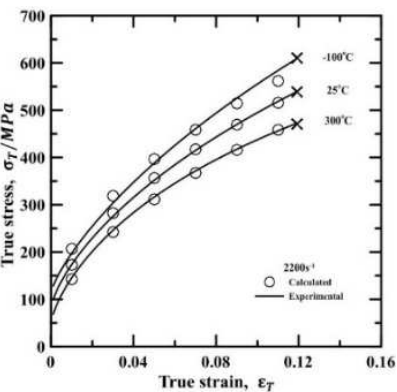

(b)
Fig. 4. Comparison of predicted and experimental stress-strain curves for AZ80 specimens deformed at different temperatures and strain rates of: (a) $8 \times 10^{2} \mathrm{~s}^{-1}$, and (b) $2.2 \times 10^{3} \mathrm{~s}^{-1}$.

\subsection{Dislocation configuration and distribution}

Figures 5(a) and 5(b) show the dislocation substructures of the specimens forged at $-100^{\circ} \mathrm{C}$ under strain rates of $8 \times 10^{2} \mathrm{~s}^{-1}$ and $2.2 \times 10^{3} \mathrm{~s}^{-1}$, respectively. For a strain rate of $8 \times 10^{2} \mathrm{~s}^{-1}$, the substructure contains a large number of parallel dislocation lines (Fig. 5(a)). These lines indicate the occurrence of a significant pile-up and grouping of the dislocations during deformation, which prompts a strain hardening effect as a result. At a higher strain rate of $2.2 \times 10^{2} \mathrm{~s}^{-1}$, dislocation cell structures and an increased dislocation density are observed (Fig. 5(b)).

The greater degree of dislocation tangling associated with these dislocation cells reduces the dislocation mobility, and hence also prompts a significant increase in the flow stress and strain hardening rate.

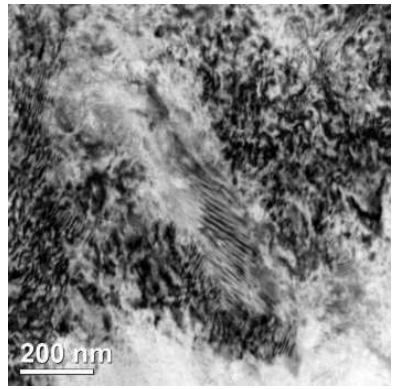

(a)

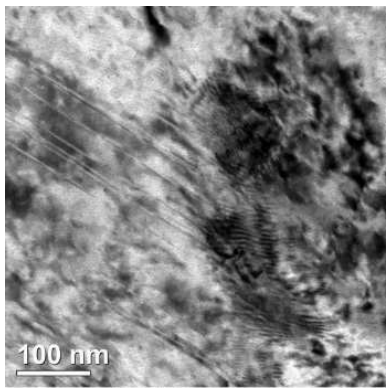

(c)

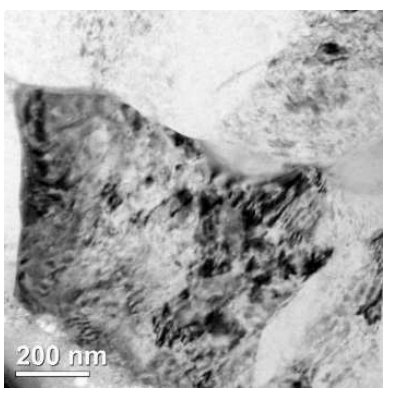

(e)

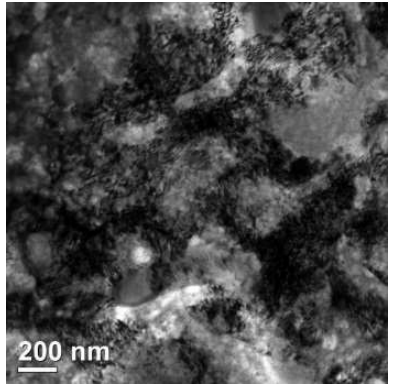

(b)

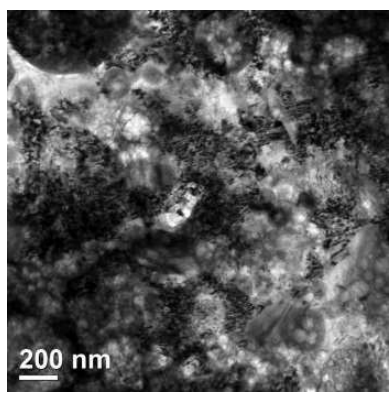

(d)

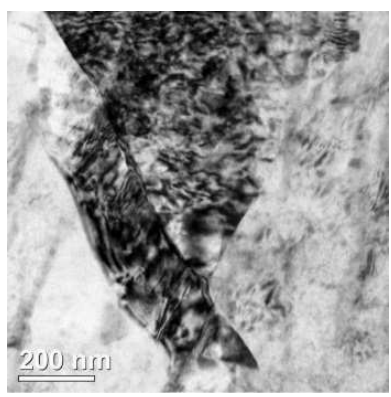

(f)
Fig. 5. TEM micrographs of specimens deformed at: (a) $100^{\circ} \mathrm{C}, 8 \times 10^{2} \mathrm{~s}^{-1}$; (b) $-100^{\circ} \mathrm{C}, 2.2 \times 10^{3} \mathrm{~s}^{-1}$; (c) $25^{\circ} \mathrm{C}, 8 \times 10^{2} \mathrm{~s}^{-1}$; (d) $25^{\circ} \mathrm{C}, 2.2 \times 10^{3} \mathrm{~s}^{-1}$; (e) $300^{\circ} \mathrm{C}, 8 \times 10^{2} \mathrm{~s}^{-1}$; and (f) $300^{\circ} \mathrm{C}, 2.2 \times 10^{3} \mathrm{~s}^{-}$

Figures 5(c) and 5(d) show the dislocation substructures of the specimens forged at $25^{\circ} \mathrm{C}$ under strain rates of $8 \times 10^{2} \mathrm{~s}^{-1}$ and $2.2 \times 10^{3} \mathrm{~s}^{-1}$, respectively. As for the specimens deformed at a lower temperature of $100^{\circ} \mathrm{C}$, the substructures are characterised by dislocation pile-up and grouping under a strain rate of $8 \times 10^{2} \mathrm{~s}^{-1}$ (Fig. 5(c)) and dislocation cells at $2.2 \times 10^{3} \mathrm{~s}^{-1}$ (Fig.5(d)). The dislocation density increases with an increasing strain rate. However, for each of the considered strain rates, the dislocation density is relatively lower, and the cell size relatively larger, than that in the specimen deformed at the same strain rate but a lower temperature of $-100^{\circ} \mathrm{C}$.

The lower dislocation density and greater cell size at higher temperatures leads to a loss in flow resistance (as shown in Fig. 1). For the specimens forged at $300^{\circ} \mathrm{C}$, the dislocation density again increases with an increasing strain rate (Fig. 5(e)) and Fig. 5(f)). However, compared with the specimens forged at $-100{ }^{\circ} \mathrm{C}$ and $25{ }^{\circ} \mathrm{C}$, the 
elevated deformation temperature reduces the dislocation density and provides the dislocations with the thermal energy required to overcome obstacles to motion. Consequently, a significant reduction in the flow resistance occurs.

The TEM images presented in Fig. 5 show that the dislocation density depends strongly on the strain rate and temperature, and has a significant effect on the flow stress. According to the Bailey-Hirsch model, the flow stress varies linearly with the square root of the dislocation density as follows [11].

$$
\sigma=\sigma_{0}-\sigma_{1} \mathrm{~Gb} \rho^{1 / 2}
$$

where $\sigma_{0}$ is the initial yield stress of the material, $\alpha_{1}$ is a material constant, $G$ is the shear modulus, $b$ is the Burgers vector, and $\rho$ is the dislocation density. Substituting values of $\mathrm{G}=17 \mathrm{GPa}[12], \mathrm{b}=3.2 \times 10-10 \mathrm{~m}$ $[13]$ and $\sigma_{0}=240 \mathrm{MPa}$ (as measured using a Saginomiya 100 metal forming machine) into Eq. (4), $\alpha_{1}$ is found to have a value of 0.36 for the present AZ80 specimens. Figure 6 compares the results obtained from Eq. (4) for the variation of the flow stress with the square root of the dislocation density with the experimental measurements.

It is observed that a good agreement exists between the two sets of results. In other words, the Bailey-Hirsch model provides a good description of the dependence of the flow stress on the substructure dislocation density for the present AZ80 magnesium alloy specimens.

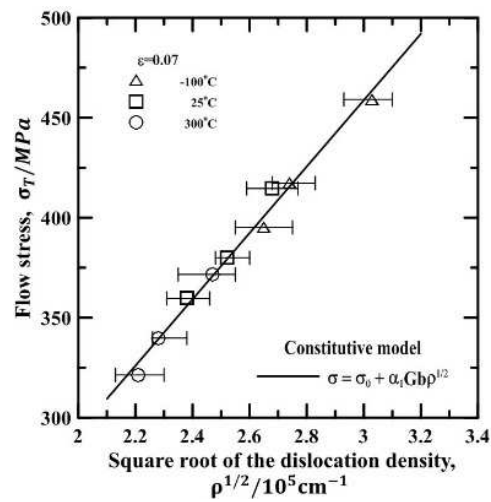

Fig. 6. Variation of flow stress with square root of dislocation density given constant true strain of 0.07 .

\section{Conclusions}

The impact deformation behaviour of AZ80 magnesium alloy have been investigated at strain rates ranging from $8 \times 10^{2} \mathrm{~s}^{-1}$ to $2.2 \times 10^{3} \mathrm{~s}^{-1}$ and temperatures of $-100{ }^{\circ} \mathrm{C}, 25$ ${ }^{\circ} \mathrm{C}$ and $300{ }^{\circ} \mathrm{C}$ using a compressive split-Hopkinson pressure bar (SHPB) system. It has been shown that the flow stress increases significantly with increasing strain rate or decreasing temperature. The strain rate sensitivity is enhanced at higher strain rates (i.e., $1.5 \times 10^{3} \mathrm{~s}^{-1}$ to $\left.2.2 \times 10^{3} \mathrm{~s}^{-1}\right)$. The stress-strain values predicted by the Zerilli-Armstrong hcp constitutive equation for the AZ80 specimens are in good agreement with the experimental results for all of the considered strain rates and temperatures. TEM observations show that the dislocation density increases with increasing strain rate, but decreases with increasing temperature. The higher dislocation density impedes dislocation motion and therefore results in a strengthening effect. Finally, the flow stress varies linearly with the square root of the dislocation density, as predicted by the Bailey-Hirsch model.

The authors gratefully acknowledge the financial support provided to this study by the Ministry of Science and Technology of the Republic of China under Grant No. MOST 103-2221-E-006-036.

\section{References}

1. Q. Guo, H. G. Yan, Z. H. Chen and H. Zhang, Mater. Charact. 58, 162 (2007)

2. Y. Kojima, Mater. Sci. Forum. 350-351, 3 (2000)

3. P. Zhang, and J. Lindemann, Scripta Mater. 52, 485 (2005)

4. Y. Uematsu, K. Tokaji, M. Kamakura, K. Uchida, H. Shibata, and N. Bekku, Mater. Sci. Eng. A. 434, 131 (2006)

5. S. Mueller, K. Mueller, H. Tao, and W. Reimers, Int. J. Mater. Res. 97, 1384 (2006)

6. T. Nakajima, M. Takeda, and T. Endo, Mater. Trans. 47, 1098 (2006)

7. J. Koike, T. Kobayashi, T. Mukai, H. Watanabe, M. Suzuki, K. Maruyama, and K. Higashi, Acta Materialia. 51, 2055 (2003)

8. M. Marya, G. R. Edwards, and S. Liu, Welding Journal. 83, 203s (2004)

9. R. K. Ham, Phil. Mag. 6, 1183 (1961)

10. F. J. Zerilli, and R. W. Armstrong, High strain rate effects on polymer, metal and ceramic matrix composites and other advanced materials, ASME1995. pp. 121 (1995)

11. Y. Tomota, P. Lukas, S. Harjo, J. H. Park, N. Tsuchida, and D. Neov, Acta Mater. 51, 819 (2003)

12. J. Jain, W. J. Poole, and C. W. Sinclair, Mater. Sci. Eng. A. 547, 128 (2012)

13. J. Jain, J. Zou, W. Poole, and C. W. Sinclair, Magnesium Technology, San Francisco, TMS. 503 (2009) 